\title{
Wideband Square Microstrip Antenna using Meandered Finite Ground Plane
}

\author{
Alok Agarwal \\ Shri Jagdish Prasad Jhabarmal Tibrewala \\ University, Jhunjhunu, (Rajasthan), India
}

\author{
P.K. Singhal \\ Department of Electronics, Madhav Institute of \\ Technology \& Science, Gwalior (M.P.), India
}

\begin{abstract}
This paper presents a compact square microstrip patch antenna design with meandered finite ground plane to enhance the impedance bandwidth. If this meandered finite ground plane antenna design is compared with conventional microstrip patch antenna design of the same design parameter with infinite ground plane (which gives bandwidth 2-3\%), it is observed that this meandered finite ground plane antenna design gives the impedance bandwidth about $12.8 \%$ of the center frequency at $1.87 \mathrm{GHz}$. The antenna design is compact and optimized for wireless communication applications. The electromagnetic simulation of the proposed antenna has been carried out using IE3D software of Zeland Software.
\end{abstract}

General Terms - microstrip patch antenna, design specification.

Keywords - impedance bandwidth, directivity, return loss, VSWR.

\section{INTRODUCTION}

Compact microstrip antennas have recently received much attention due to the increasing demand of small antennas for personal communications equipment. For achieving microstrip antennas with a reduced size at a fixed operating frequency, the use of a high-permittivity substrate is an effective method. By applying the meandering method to the finite ground plane of a microstrip antenna, a significant lowering of the antenna's fundamental resonant frequency to the patch-meandering method can be achieved. In addition, the impedance bandwidth and antenna gain can be enhanced, which is a great advantage of the ground-meandering method over the patch-meandering one. The antenna's ground plane can be meandered by inserting several meandering slits at its edges or slot can be introduced at the ground plane. The obtained impedance bandwidth for a compact design with a meandered ground plane can be greater than that of the corresponding conventional microstrip antenna [3].

Conventional microstrip antennas in general have a conducting patch printed on a grounded microwave substrate, and have the attractive features of low profile, light weight, easy fabrication, and conformability to mounting. However, microstrip antennas inherently have a narrow bandwidth, and bandwidth enhancement is usually demanded for practical applications.
The, size reduction and bandwidth enhancement are becoming major design considerations for practical applications of microstrip antennas. For this reason, studies to achieve compact and broadband operations of microstrip antennas have greatly increased [1-10]. Microstrip patch antennas are widely implemented in many commercial applications of wireless communication. As the demand for increased electronic mobility grows the need for small handsets are most likely increased. Microstrip patch antennas are manufactured using printed circuit technology, so that mass production can be achieved at a low cost. The electromagnetic simulation of the proposed antenna has been carried out using IE3D software of Zeland Software. VSWR, input impedance, return loss, smith chart, directivity, antenna gain, radiating efficiency, radiation pattern etc. can be evaluated using IE3D software.

\section{ANTENNA DESIGN SPECIFICATION}

In this proposed antenna design, the slot loaded square patch is printed on inexpensive FR4 (copper-cladded plate) having dielectric constant $(\mathrm{Cr})$ of 4.4 , loss tangent $\tan \delta=0.02$ and height $1.6 \mathrm{~mm}$. In this antenna design, an effort has been made to enhance the bandwidth due to slot loaded square micro strip patch antenna with meandered finite ground plane. The 50-ohm coaxial cable with SMA connector is used for feeding the microstrip patch antenna. Figure 1 shows the top view of slot loaded square microstrip patch antenna of proposed antenna design. Figure 2 shows the back view of slot loaded square microstrip patch antenna (i.e. meandered finite ground plane) of proposed antenna design. In this proposed antenna design, with center frequency $\mathrm{f}_{0}=1.87 \mathrm{GHz}$ within the frequency range 1 $\mathrm{GHz}$ to $3 \mathrm{GHz}$, step frequency $=0.01 \mathrm{GHz}$, In this proposed antenna design, length of patch $\mathrm{L}=30 \mathrm{~mm}$, width of patch $\mathrm{W}=$ $30 \mathrm{~mm}$, with finite ground plane of the same dimension as that of square microstrip patch and feed point locations at the patch is $(0.5,9)$. Figure 3 shows the variation of return loss with frequency for the proposed antenna design; the impedance bandwidth is taken from the $10-\mathrm{dB}$ return loss. Figure 4 shows the variation of VSWR with frequency for the proposed antenna design, A VSWR of 2:1 or less is considered for the impedance bandwidth. Figure 5 shows the variation of directivity (in $\mathrm{dBi}$ ) with frequency for the proposed antenna design. Figure 6 shows the radiation pattern for the proposed antenna design at the center frequency $1.87 \mathrm{GHz}$. Figure 7 shows the Impedance loci (Smith chart) for the proposed antenna design. Here due to slot loaded square micro strip patch antenna with meandered finite ground plane of this antenna design; the impedance bandwidth, determined from the $10-\mathrm{dB}$ return loss, is about $12.8 \%$ of the center frequency at $1.87 \mathrm{GHz}$. 


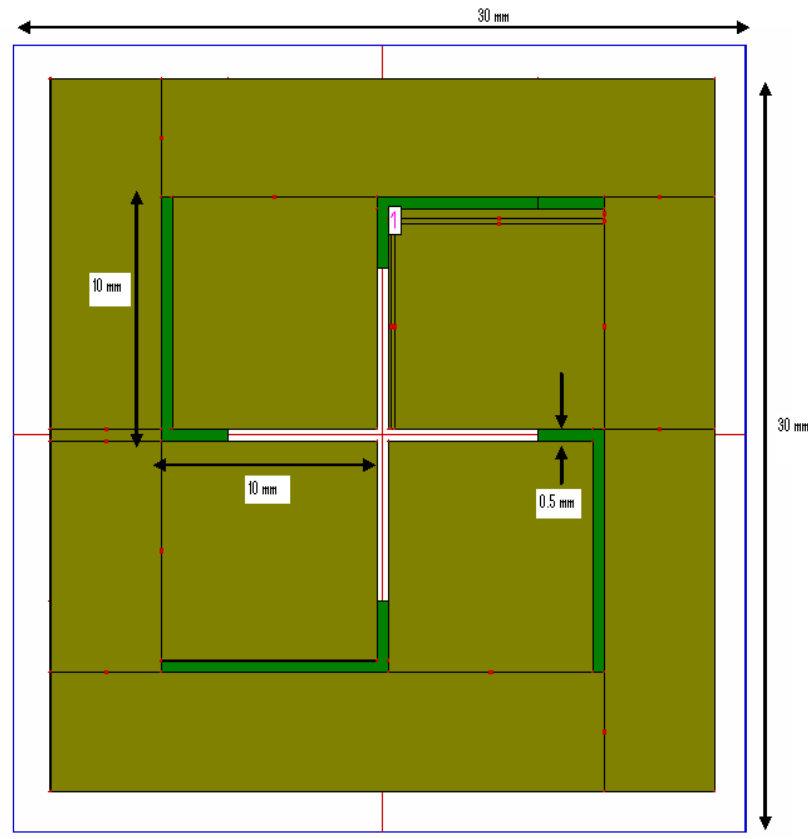

Figure 1: Front view of slot loaded square microstrip patch antenna

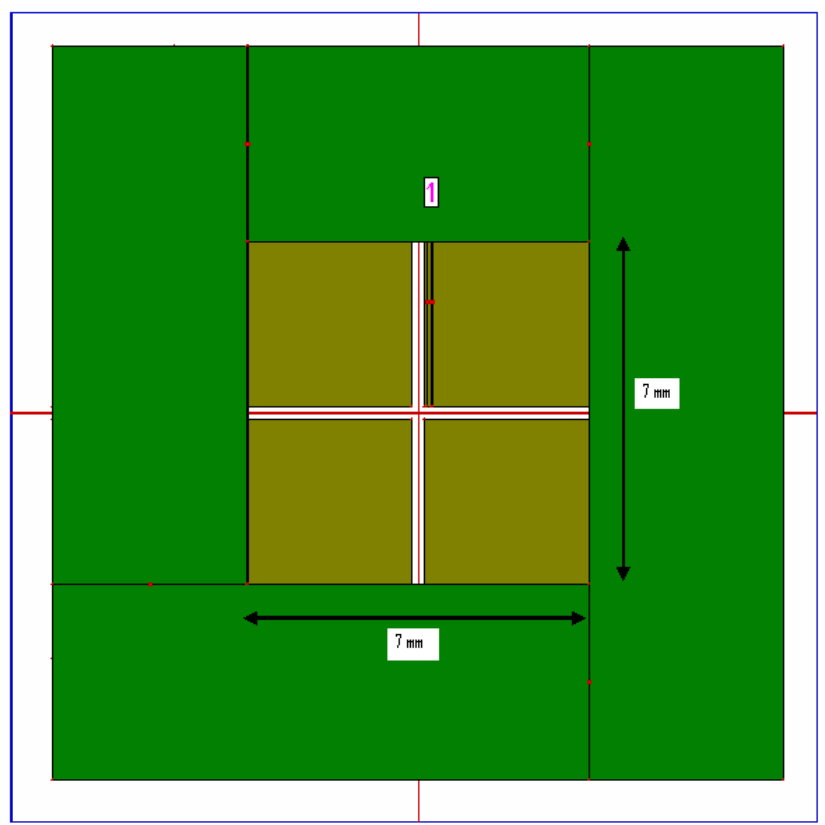

Figure 2: Back view of slot loaded square microstrip patch antenna (i.e. meandered finite ground plane)

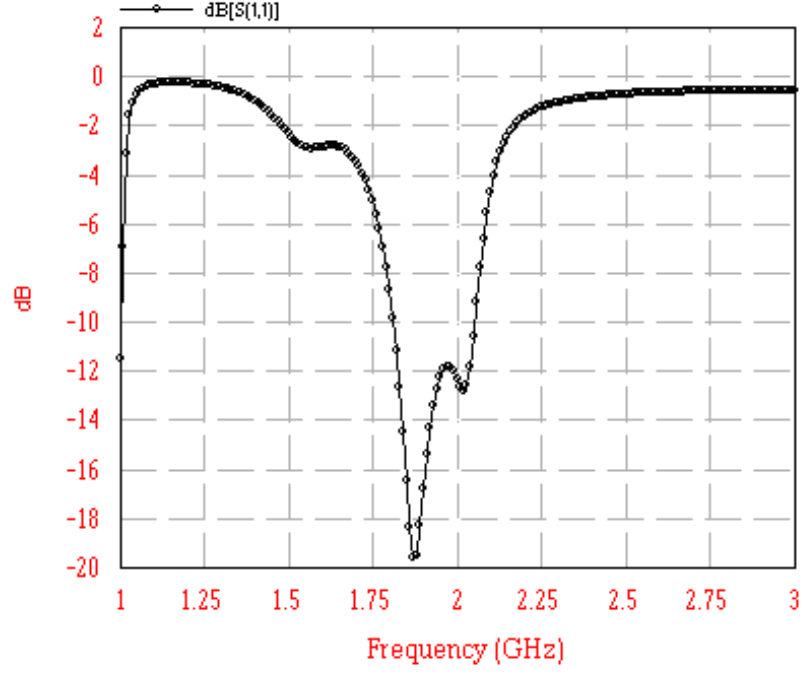

Figure 3: Variation of return loss with frequency for proposed antenna design

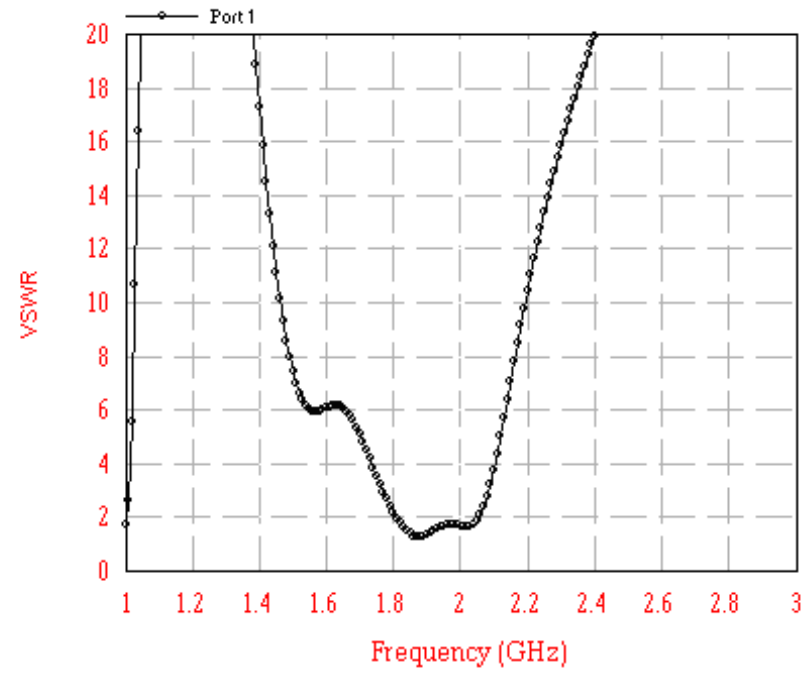

Figure 4: Variation of VSWR with frequency for proposed antenna design 


\section{Directivity Vs. Frequency}

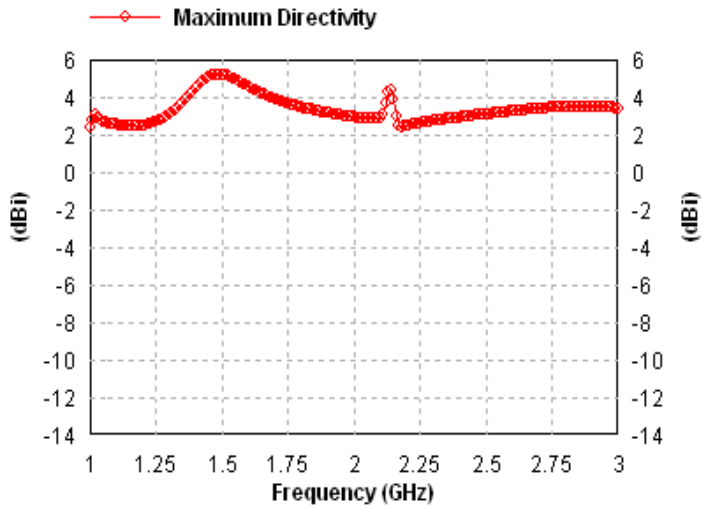

Figure 5: Variation of directivity with frequency for proposed antenna design

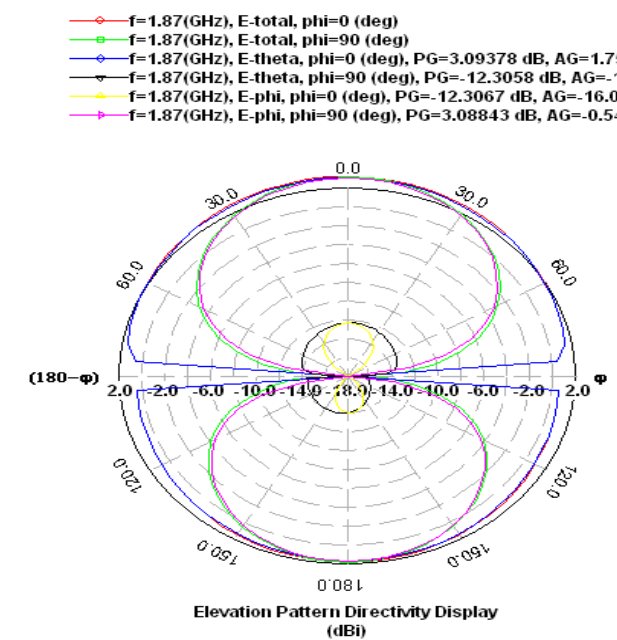

Figure 6: Radiation Pattern for proposed antenna design

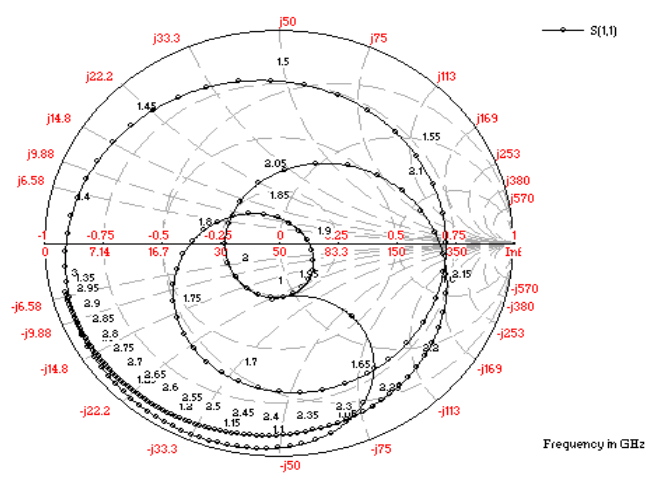

Figure 7: Impedance loci for proposed antenna design

\section{RESULT AND DISCUSSIONS}

The simulation result of the proposed antenna design has been carried out by using IE3D software. For slot loaded compact square microstrip patch antenna with meandered finite ground plane of this antenna design; the impedance bandwidth, determined from the $10-\mathrm{dB}$ return loss, is about $12.8 \%$ of the center frequency at $1.87 \mathrm{GHz}$. Which is very much increased and optimized as compared with conventional microstrip patch antenna design of the same design parameter with infinite ground plane and can be utilized for wireless communication applications.

\section{REFERENCES}

[1] Milligan, T. A., "Modern Antenna Design", John Wiley \& Sons, Hoboken, New Jersey, 2005.

[2] Garg, R., P. Bhartia, I. Bahl, and A. Ittipiboon, "Microstrip Antenna Design Handbook", Artech House, Boston, London, 2001.

[3] Wong, K. L., "Compact and Broadband Microstrip Antenna”, John Wiley \& Sones, New York, 2002.

[4] Kumar, G. and K. P. Ray, "Broadband Microstrip Antennas", Artech House, USA, 2003.

[5] Pozar, D.M. and D.H.Schaubert, Microstrip Antennas: The Analysis and Design of Microstrip Antennas and Arrays, New York: IEEE Press, 1995.

[6] C.A.Balanis, Antenna Theory Analysis and Design. $3^{\text {rd }}$ ed., Hoboken, New Jersey: Wiley, 2005

[7] Ray, K. P., S. Ghosh, and K. Nirmala, "Multilayer multi resonator circular microstrip antennas for broadband and dualband operations," Microwave and Optical Technology Letters, Vol. 47, No. 5, 489-494, Dec. 2005.

[8] Ghassemi, N., M. H. Neshati, and J. Rashed-Mohassel, "A multilayer multiresonator aperture coupled microstrip antenna for ultra wideband operations," Proc. IEEE Applied Electromagnetic Conference 2007, Kolkata, India, December 19-20, 2007.

[9] Zehforoosh, Y., C. Ghobadi, and J. Nourinia, "Antenna design for ultra wideband applications using a new multilayer structure," PIER Online, Vol. 2, No. 6, 544-549, 2006.

[10] Kim, T., J. Choi, and J. S. Jeon, "Design of a wideband microstrip array antenna for PCS and IMT-2000 service,' Microwave and Optical Technology Letters, Vol. 30, No. 4, 261-265, Aug. 2001. 